\title{
Development of territories through the construction of sports facilities
}

\author{
Lidya Shershova*, Elena Golovina, Yulia Gurenko, and Olga Tomashevskaya \\ Immanuel Kant Baltic Federal University, 14 Nevskiy St, 236016 Kaliningrad, Russian Federation
}

\begin{abstract}
The approach to the development of territories through the construction of sports facilities on the example of the city of Kaliningrad (Northwestern Federal District, Russia) is considered. The results of the implementation of state target programs for the formation of the urban environment are analysed. These programs provide the opportunity to engage in physical education and sports on equipped sports grounds. The results of monitoring the use of sports facilities for physical culture and sports in the city of Kaliningrad are presented. The conditions for increasing the volume of physical activity of young people through the system of attracting them to systematic physical culture and sports on doorstep sports grounds have been determined.
\end{abstract}

\section{Introduction}

Today, in many regions of Russia, special attention is paid to the sustainable development of territories through the provision of a comfortable and favorable environment for life [1]. Special attention is paid to the promotion of physical culture and sports activities through the popularization of a healthy lifestyle. The development of mass sports activities opens up new horizons for adjusting territorial development plans.

Physical activity is an essential element of a healthy lifestyle, has a beneficial effect not only on the harmonious development of a person's personality, but also on his functional capabilities, increases physical and mental performance, strengthens health and prevents diseases [2].

Many scientists are engaged in the development of physical culture and sports through urban planning policy. The work of G.P. Akmen highlights the problems in the field of physical culture and sports and offers urban planning measures to eliminate them. The author also emphasizes that one of the active and significant participants in the movement to promote a healthy lifestyle is student youth [3]. In this regard, the creation of conditions for those who want to go for sports on sports grounds, and not only in the form of organized forms of physical education at a university, becomes an urgent problem.

Scientific works of many authors show that the development of territories and the urban environment in the formation of a healthy lifestyle is of decisive importance [4]. Since 2013, the state program "Formation of a modern urban environment" has been implemented in the Kaliningrad region [5]. The main goal of this program is "the integrated development

\footnotetext{
*Corresponding author: shershova@mail.ru
} 
of modern urban infrastructure based on common approaches" [6]. Within the framework of the program, both the improvement of the territories adjacent to residential buildings and the courtyards and objects of the urban environment are supposed. On the example of large cities in Russia, we can observe the active construction of municipal outdoor and indoor sports facilities [7]. At the moment, the provision of sports and physical culture grounds for the residents of Russia is set at $2 \mathrm{~m}^{2}$ per person. Based on these data and the population of the country, we can conclude that there is a significant lack of territories for physical culture and sports. According to Rosstat, there were about 146 million permanent residents in Russia as of January 1, 2020, while the country ranks ninth in the world in terms of population [8].

In this regard, one of the main targets of the Strategy for the development of physical culture and sports in the Russian Federation (approved by the Order of the Government of the Russian Federation dated 07.08.2009 No. 1101-r) is to increase the overall level of provision of the population with sports facilities [9].

At the same time, the problem of the material and technical base for physical education in the open air, the lack of specialized sports grounds, which are designed in compliance with all modern norms and requirements, does not lose its relevance. Research of L.A. Atroshchenko showed that certain principles must be observed in the improvement of sports grounds. First of all, sports facilities should be multifunctional and provide appropriate conditions for holding mass events. Sports grounds should be able to be used by all age groups of the population, and should also be focused on the most popular sports [10]. The more common types of such sports grounds are multifunctional physical and sports grounds, which may include: playgrounds for sports games, universal sports grounds, sports and developmental and gymnastic grounds, as well as exercise equipment and obstacle courses. However, a relatively large proportion of sports facilities are located on the territory of kindergartens and schools, where sanitary norms and safety measures prohibit the flow of outside visitors, which does not provide a full-fledged opportunity for the development of physical culture and sports movement.

\section{Materials and methods}

The study of the problems of territorial development through the formation of a comfortable urban environment, taking into account all modern aspects of the improvement of sports grounds, are interconnected with the current problems of territory management, with the priority programs for the construction of sports facilities and related infrastructure, and are interdisciplinary in nature.

The theoretical and methodological basis of the research is based on the works of domestic specialists and scientists in the field of research of the development of territories, taking into account the formation of an environment for physical culture and sports.

The informational basis of the research is the official data of the results of the implementation of the national project in the Kaliningrad region and the results of the monitoring carried out by the authors among the students of the Immanuel Kant Baltic Federal University. The purpose of the monitoring was to determine the availability and frequency of use of sports grounds for physical culture and outdoor sports. More than a hundred young people took part in the survey, of which $52.7 \%$ were males and $47.3 \%$ females.

The aim of the study is to analyse the existing conditions of the urban environment, guaranteeing the opportunity for student youth to systematically engage in physical culture.

Research objectives: 
1. To conduct monitoring of the implementation of the program "Formation of a modern urban environment" from the standpoint of the formation of doorstep places for physical culture and sports.

2. To study modern conditions for physical education and sports in Kaliningrad.

3. To reveal the motivation of residents to systematic physical education in modern urban conditions.

In order to study the motivation of residents to systematically engage in sports, the authors of the article developed a questionnaire for monitoring, the analysis of the data of which formed the basis of the study.

\section{Results and discussion}

Within the framework of the state program "Formation of a modern urban environment", the implementation of which is planned for 2022 inclusive, the number of landscaped areas in the Kaliningrad region, in the settlements of municipalities of the region per year is $136.7 \%$ [12]. Funding for the program, starting in 2018, is carried out at the expense of the regional and federal budgets (Fig. 1.)

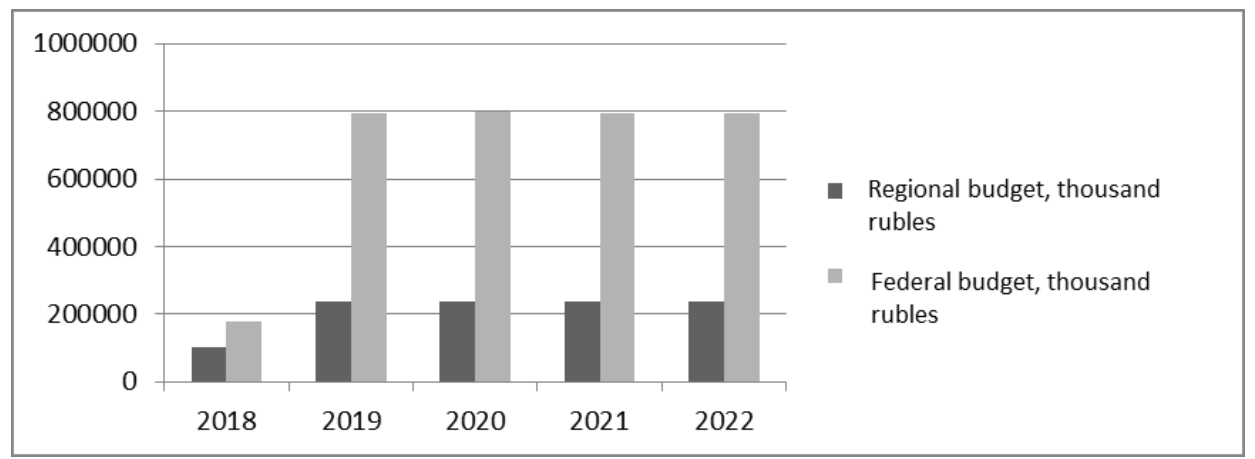

Fig. 1. Financing of the program "Formation of a modern urban environment" [12]. Source: authors' own calculations

Throughout the entire period of the program, places of leisure are being created for the population. In cities, conditions for mass recreation and aesthetic appearance are being improved, including an increase in the number of children's playgrounds and sports grounds. According to the annual report on the progress of implementation and assessment of the effectiveness of state programs of the Kaliningrad region at the end of 2018, within the framework of the programs "Formation of a modern urban environment" and "Development of infrastructure for physical culture and sports", universal sports grounds were built in a number of settlements (Partizanskoye village (Bagrationovsky city district) and in the city of Chernyakhovsk) [12]. Ten sports grounds were arranged, including workout training grounds (in the cities of Zelenogradsk, Polessk, Chernyakhovsk, Baltiysk, Kaliningrad and the settlements of Yagodnoye (Nesterovsky urban district), Domnovo (Pravdinsky urban district)). Reconstruction of the city stadiums was carried out (Pravdinsk, Zelenogradsk, Chernyakhovsk). Much work has been done to equip the running tracks and athletics sectors at the Baltika stadium (Kaliningrad). As part of the preparation program for the 2018 FIFA World Cup matches in Kaliningrad, the Kaliningrad Arena stadium for 35 thousand spectators was commissioned, three training grounds were reconstructed in Kaliningrad, and a training ground was built in the city of Svetlogorsk. The number of sports facilities per 100 thousand people of the population of the Kaliningrad region was 219 units. For the construction of these facilities, builders were involved from 
all regions of Russia, countries of near and far abroad. Graduates of the "Construction" program of the Immanuel Kant Baltic Federal University are also actively involved in the construction of sports facilities [13].

Earlier, in their studies on the problem of the formation of the urban environment, T.V. Pungin and V.L. Pungina showed that young people in the age group of 16-30 years old are most interested in the development of the urban environment for comfortable physical education [14]. As noted in the studies of A.V. Kabachkov, V.V. Fomchenko and Yu.S. Frolov, the level of physical activity is influenced by both the individual attitude of the trainees and the educational process in general. The authors note that during the period of academic semesters and examination sessions, the physical activity of students is significantly reduced $[15,16]$.

At the moment, 1108 flat sports facilities function on the territory of the Kaliningrad region, 420 of them only in the city of Kaliningrad. An analysis of the monitoring carried out among students of the Immanuel Kant Baltic Federal University showed that $77.6 \%$ of students had weekly physical activity below the required level (8-10 hours per week). It was determined that $48.3 \%$ of students devote only 2 to 4 hours a week to physical activity and only $22.4 \%$ of respondents observe the minimum volume of physical activity per week.. In addition to the main occupations at the university, $20.7 \%$ of the respondents have classes in open areas. A rather low percentage of young people (1.7\%) go in for sports more than 8 hours a week, which is confirmed by the research of A.V. Kabachkov et al. (Fig. 2).

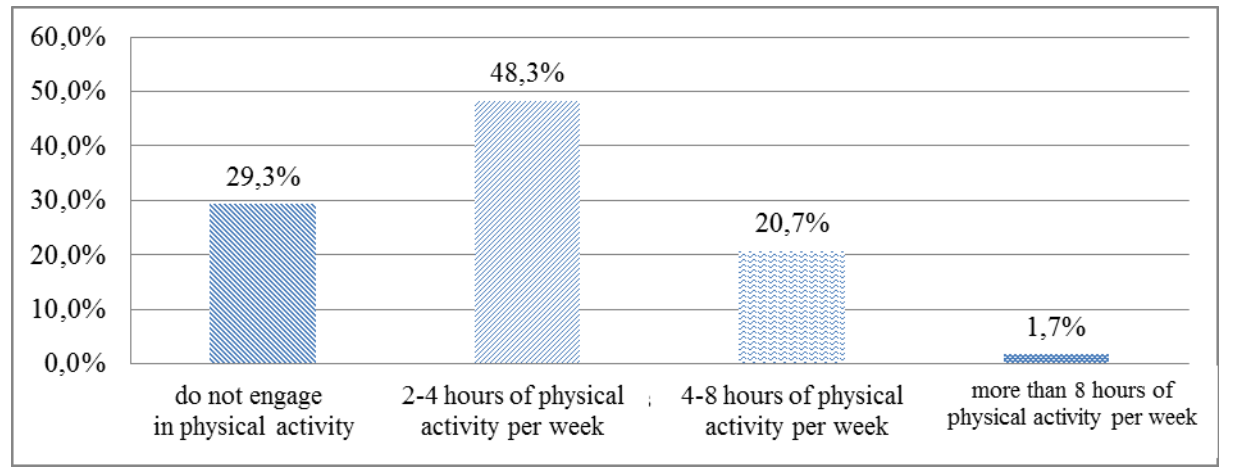

Fig. 2. Weekly physical activity of students. Source: authors' own calculations

The results of the last survey showed that almost $72.5 \%$ of respondents prefer passive recreation. Only $17.3 \%$ regularly visit outdoor sports grounds, hike, run cross-country and lead an active lifestyle. Students explain the low level of activity by the workload of the educational process and the lack of free time. In the work of A.A. Nikitin et al., devoted to the analysis of the attitude and value orientations of first-year students to physical culture at the university, it was noted that physical culture has enormous values and opportunities for physical improvement of a person, capable of influencing his value orientations [17]. The results of the survey showed that all the students who took part in the survey understand the importance of physical education for their health. According to the monitoring, $37.9 \%$ of the interviewees noted that physical activity is expressed only in a walk "on foot to the university and back." More than half of the respondents (57\%) assess their daily physical activity as insufficient, and their state of health satisfactory (69\%). Among the components of a healthy lifestyle, "sports" occupy only the fourth place, and is $15.5 \%$ of the respondents. The majority of students believe that adhering to the principles of a healthy lifestyle is "not the most important thing" $(58.6 \%)$. This proves that it is necessary to carry out purposeful work with students, expand and replenish their knowledge in the field of physical culture and a healthy lifestyle, as well as form their need for physical culture. 
In the course of the study, the most preferable objects for physical education were identified. One of the leading places $(34.5 \%)$ was given by the respondents to fitness centers, $27.6 \%$ prefer to work out in outdoor sports grounds, and $25.8 \%$ go to the swimming pool. A fairly high percentage (34.5\%) noted that they do not use sports grounds, due to the absence of them near the house. It is for the same reason that $88 \%$ of the respondents did not use the open sports ground located under the flyover bridge ("M.O.S.T.") in the city of Kaliningrad (Fig. 3).

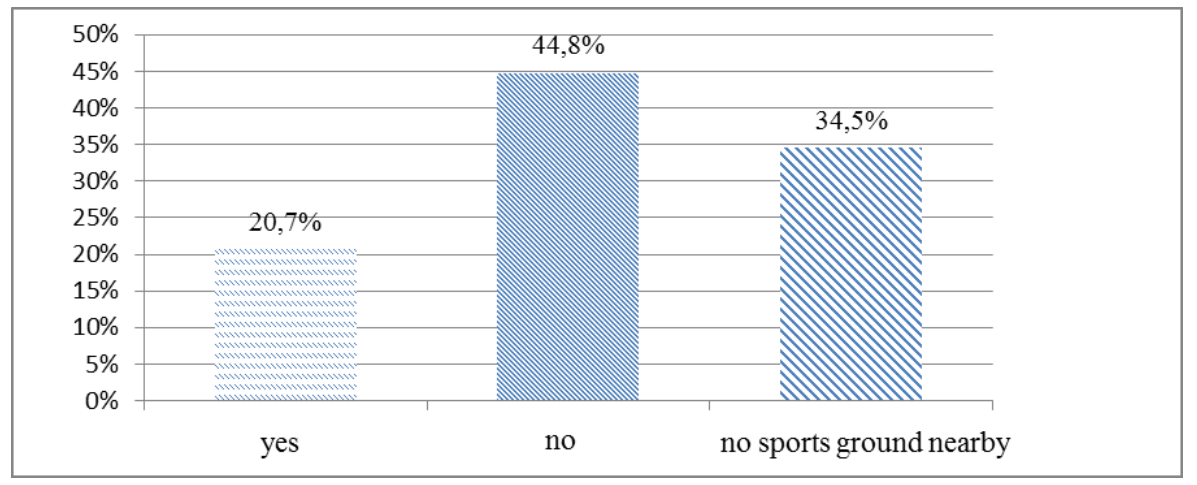

Fig. 3. Demand for places of active leisure. Source: authors' own calculations

The results of the survey showed that there is free access to most of the territories and sites for physical education in the city (77.6\% of the respondents). At the same time, the respondents noted that some sports grounds are in an unsatisfactory condition and require reconstruction $-29.3 \%$. The state of the sports grounds largely depends on the careful attitude and proper operation of the users themselves. Unfortunately, free access to equipment at the sites contributes to the manifestation of vandalism. Figure 4 shows a diagram of the peculiarities of the technical condition of sports facilities in Kaliningrad. About 30 percent of active leisure and sports grounds are in satisfactory condition.

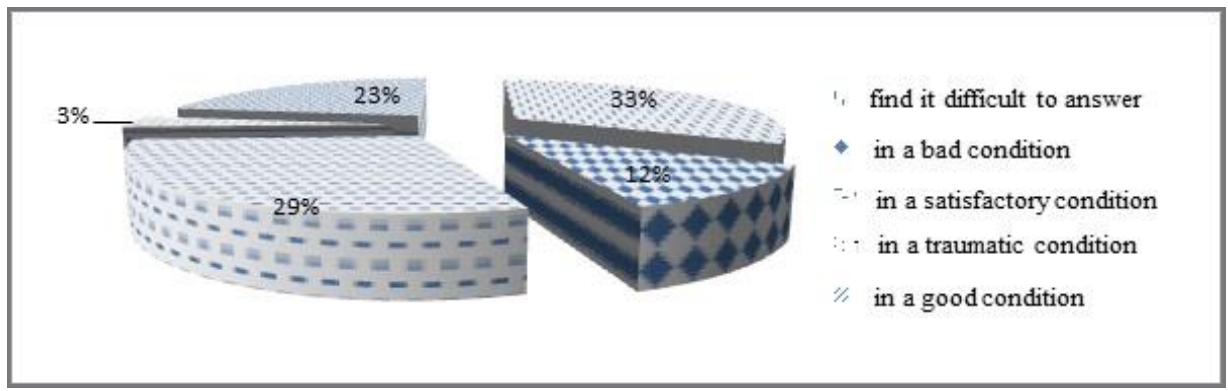

Fig. 4. Features of the technical condition of sports facilities (on the example of the city of Kaliningrad). Source: authors' own calculation

Insufficient equipment of flat sports facilities was noted by $69 \%$ of respondents. Considering the elements of the improvement of the urban environment, about $18.9 \%$ of young people would like to see more sports grounds and territories for physical culture and sports in their microdistrict, and $22.4 \%$ of respondents preferred more green spaces and arrangement of lawns. 


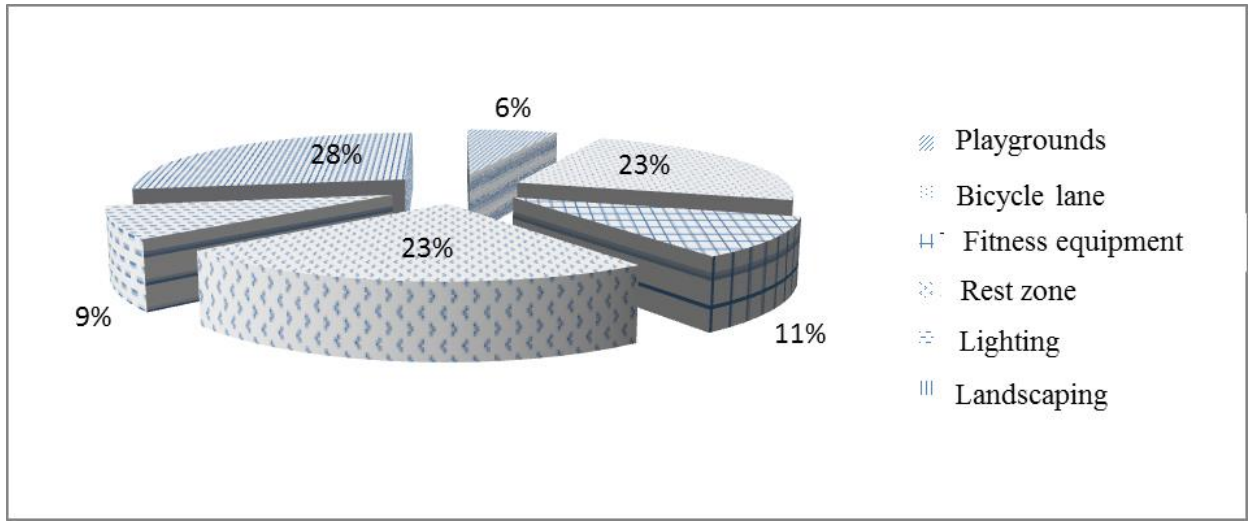

Fig. 5. Elements of improvement of the urban environment. Source: authors' own calculations.

Analysis of the research results showed that $93.1 \%$ of respondents consider the number of sports facilities in the city insufficient.

The majority of respondents $(64.9 \%)$ believe that areas for physical culture and sports should be within walking distance from their place of residence. One of the reasons why students do not systematically engage in physical culture and sports is "the absence of a sports ground near the house" (24.1\%) (Fig. 6).

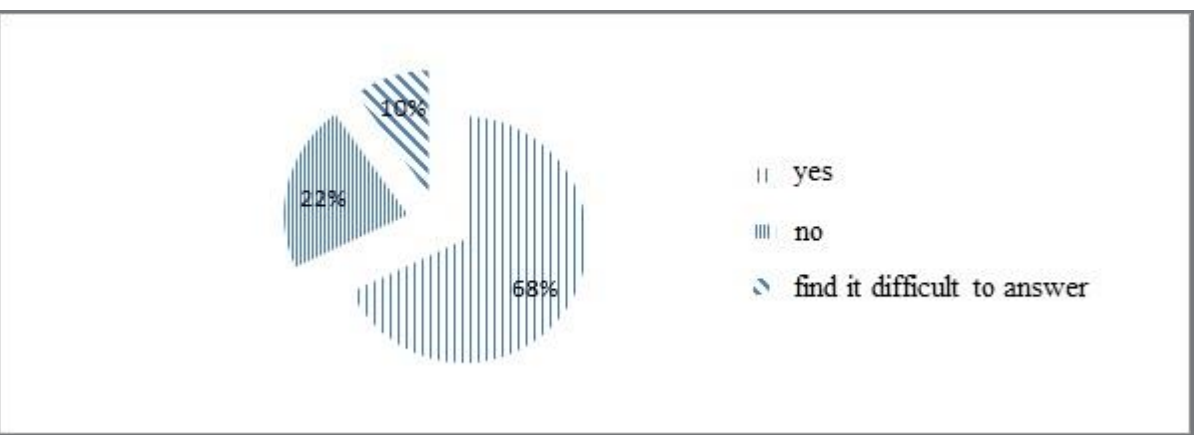

Fig. 6. Aspects of the demand for sports grounds. Source: authors' own calculations

\section{Conclusions}

1. Analysis of the results of the implementation of the program "Formation of a modern urban environment" in the Kaliningrad region showed that certain conditions have been created in a number of municipalities for physical culture and sports of the population.

2. It was found that the formation of a modern comfortable urban environment contributes to the solution of the issues of increasing the volume of physical activity of student youth, as well as the formation of their desire for a healthy lifestyle and physical improvement.

3. It was revealed that more than $70 \%$ of respondents are ready to systematically engage in physical culture on sports grounds and territories of the city of Kaliningrad at doorstep sports facilities.

4. For the effective use of the facilities already put into operation for physical education and sports, it is necessary to equip sports grounds with information and methodological materials for those involved. 
The authors would like to thank the students of the Immanuel Kant Baltic Federal University (Kaliningrad, Russia) for their responsiveness and assistance in monitoring.

\section{References}

1. Decree of the President of the Russian Federation of December 31, 2015 N 683 "On the National Security Strategy of the Russian Federation" (2015), https://rg.ru/

2. Yu. V. Gurenko, A.A. Zaitsev, M.Ya. Muravieva, V.K. Pelmenev, IKBFU's Vestnik Philology, pedagogy, and psychology, 88 (2017)

3. G.P. Akmen, Molodoy uchenyy 183 (2017)

4. L.A. Sapegin, Molodoy uchenyy, 23(261) (2019)

5. Decree of the Government of the Kaliningrad region of February 27, 2013 No. 119 "On approval of the list of state programs of the Kaliningrad region", (2013) https://gov39.ru/

6. Passport of the priority project "Formation of a comfortable urban environment" (2018)

7. Priority project "Formation of a comfortable urban environment" (2018)

8. The population of the Russian Federation by municipalities (2020) https://rosstat.gov.ru/

9. Development of physical culture and sports, Official website of the Ministry of Sports of the Russian Federation, (2017)

10. L.A. Atroshchenko, Vestnik MGUU, 3 (2015)

11. Decree of the government of the Kaliningrad region of February 27, 2013 No. 119 "On approval of the list of state programs of the Kaliningrad region (2013) https://gov39.ru/

12. Consolidated annual report on the implementation and evaluation of the effectiveness of state programs of the Kaliningrad region at the end of 2018 (2018) https://gov39.ru/

13. L. Shershova, E. Kurochkin, I. Nuzhina, MATEC Web of Conf, 25105015 (2018)

14. T.V. Pungin, V.L. Pungina Problems and prospects for the development of engineering and construction science and education: Materials of the I All-Russian Scientific and Practical Conference (2017)

15. N.A. Kuznetsova, I.S. Kazakova Science of the young - the future of Russia Proceedings of the 3rd International Scientific Conference of promising developments of young scientists (2018)

16. A.V. Kabachkova, V.V. Fomchenko, Yu.S. Frolova, Tomsk State University Journal, $392(2015)$

17. A.A. Nikitina, K.A. Devyatova, E.A. Golovina, S.V. Spodenko, Nauchnyy zhurnal Diskurs, 3 (2018) 